\title{
Analysis of three indirect methods for estimating the evapotranspiration in the agricultural zone of Chillán, Chile
}

\section{Análisis de tres métodos indirectos de estimación de la evapotranspiración para la zona} agrícola de Chillán, Chile

Fecha de entrega: 2 de noviembre 2015 Fecha de aceptación: 1 de abril 2016

\section{María Jesús Bochetti ${ }^{1}$, Enrique Muñoz ${ }^{2}$, Pedro Tume ${ }^{2}$ and Joan Bech ${ }^{3}$}

\footnotetext{
${ }^{1}$ Procter \& Gamble Chile Limitada, Avenida Presidente Riesco 5335, piso 17, Las Condes, Santiago, Chile, jesus.bochetti@gmail.com ${ }^{2}$ Departamento de Ingeniería Civil, Universidad Católica de la Santísima Concepción, Alonso de Ribera 2850, Concepción, Chile, emunozo@ucsc.cl,ptume@ucsc.cl

${ }_{3}^{3}$ Departamento de Astrononmía y Meterología, Universidad de Barcelona, Marti i Franques 1, Barcelona, Spain, jbech@ub.edu
}

Three models for estimating the daily reference evapotranspiration $E T_{o}$ are evaluated in the agricultural zone of Chillán, Chile: Penman-Monteith FAO PMF, Prietsley-Taylor PT and Hargreaves-Samani HS. The daily $E T_{0}$ values estimated through these methodologies are compared with the daily values of $E T_{o}$ estimated from pan evaporation $E T_{o} B$ data series obtained from meteorological stations of the Universidad de Concepción Campus Chillán and INIA Quilamapu, both located within Chillán's city limits. The comparison and analysis were performed with data covering a span of 13 years (1996 - 2008). Results indicate that the HS method systemically underestimates $E T_{o}$ values, particularly during dry periods. Moreover, differences between the three methods quantified with Root Mean Squared Error RMSE and Relative Differences RD computed for different time periods (1, 3, 7 and 30 days) suggest that the PT method fits better the observations, being more adequate for the agricultural area of Chillan - weekly averages yield RMSE of $1.01 \mathrm{~mm} /$ day and $R D$ of $32.8 \%$.

Keywords: reference crop evapotranspiration, pan evaporation, Chillán-Chile
Se evalúan tres modelos para la estimación de la evapotranspiración de referencia $E T_{o}$ en la zona agrícola de Chillán, Chile: Penman-Monteith FAO PMF, Prietsley-Taylor PT y Hargreaves-Samani HS. Valores diarios de ETo estimados usando dichas metodologías son comparados con valores diarios de ET, obtenidos a partir de datos de evaporación de bandeja $E T_{0} B$ de las estaciones meteorológicas Universidad de Concepción Campus Chillán e INIA Quilamapu, ambas ubicadas en la ciudad de Chillán. El análisis se llevó a cabo para un rango de datos de 13 años (1996 - 2008). La comparación de las series temporales indica que el método HS subestima sistemáticamente los valores de ETo especialmente durante periodos secos. Además, el análisis comparativo de la Raiz del Error Cuadrático Medio RECM y las Diferencias Relativas DR entre los distintos métodos evaluado para diversas ventanas temporales (1, 3, 7 y 30 dias), sugieren que el método PT resulta el más recomendable para la zona agrícola de Chillán - para promedios semanales se obtienen RECM de $1.01 \mathrm{~mm} /$ día y RD del $32.8 \%$.

Palabras clave: evaporación de referencia, evaporación de bandeja, Chillán-Chile

\section{Introduction}

Reference evapotranspiration $E T_{\mathrm{o}}$ is a key component in many hydrometorological and agricultural studies and applications. It is used for urban and agricultural planning, irrigation planning, water balance studies, and agro-climatic zoning studies, among others (Samani, 2000; Droogers and Allen, 2002). ET is the most important component in the quantification and estimation of agricultural water usage. The estimations of $E T_{\text {o }}$ are widely used and required to define water needs for crops and are also required for designing and planning irrigation systems. These estimations are used both, in the planning process of these irrigation systems and in the management of water distribution of existing systems (Droogers and 
Allen, 2002). Because of its importance in agriculture and because their values are essential to quantify the general water balance of a particular zone, it is critical to obtain the most accurate estimation of the amounts of real evapotranspiration $E T_{\mathrm{r}}$ and reference evapotranspiration (Hube, 1989; Sumner and Jacobs, 2005). The importance of evapotranspiration has triggered the development of satellite-based retrieval methods (Wang and Dickinson, 2012), such as the approach recently proposed by Sánchez et al. (2008) based on LANDSAT imagery. However, given the current limitations of those methods, there is still a need to use ground based data for practical applications such as in irrigation management of crops, particularly in arid or semi-arid environments with Mediterranean climate (Rana and Katerji, 2000). Currently there are different methods available to estimate $E T_{\mathrm{o}}$ from ground based automated observations. Therefore, evaluating these methods, knowing their advantages and limitations, their precision levels, and application limits, should be the first step before using them (Xiaoying and Erda, 2005).

There are many models based on meteorological data which allow estimating $E T_{o}$ in different climates and geographical conditions. The Penman-Monteith FAO model PMF is generally presented as a standard model for estimating $E T_{\text {o }}$ (Allen et al., 1998). The main limitation of this model is the need of many meteorological data entries which limits its applicability in areas where data is less available, especially in developing countries. Some simpler models that use parameters or variables that are commonly measured in meteorological stations are more advisable to estimate $E T_{\mathrm{o}}$ in scarce-data areas (Tabari, 2009).

Among those simpler models to calculate $E T_{\text {o }}$ are the Priestley-Taylor PT method (Priestley and Taylor, 1972), and the Hargreaves-Samani HS method (Samani, 2000; Hargreaves and Allen, 2003). The HS method is a simple method that only requires data such as temperature and latitude of the area of study. Chillán, Chile is an area of intense agricultural development and production with a significant availability of hydric resources, therefore an accurate $E T_{\text {o }}$ estimation is necessary. The objective of this study is to evaluate the level of accuracy of the simpler and the traditional models in estimating the evapotranspiration in the area of Chillán in order to recommend an option that offers security in the estimation of this variable under the scenarios of limited data availability.

\section{Materials and methods Study area and data}

The agricultural area of Chillán has a temperate Mediterranean climate with a thermal regime characterized by an annual average temperature of $14^{\circ} \mathrm{C}$, ranging from $28.8^{\circ} \mathrm{C}$, in the hottest month (January), to $3.5^{\circ} \mathrm{C}$ in the coldest month (July). The hydric regime is characterized by an average annual precipitation of $1025 \mathrm{~mm}$ and a four month dry season (December-March). The month of July is typically the rainiest with an average rainfall of $217 \mathrm{~mm}$ (Novoa et al., 1989). The Koepen-Geiger classification code of this area is Csb (Kottek et al., 2006), i.e. warm temperate with dry and warm summer, a code typically associated to Mediterranean climate. The pan evaporation reaches $1308 \mathrm{~mm}$ per year, with a minimum of $7 \mathrm{~mm}$ in June, and a maximum of $260 \mathrm{~mm}$ in January. Daily meteorological data (air temperature, relative humidity, wind velocity, solar radiation, and pan evaporation) recorded between 1996 and 2008 was used for the study. The data was collected at the meteorological stations of Universidad de Concepción Campus Chillán (36 $34^{\prime} \mathrm{S}, 7^{\circ} 06^{\prime} \mathrm{W}, 149$ masl) and INIA-Quilamapu Chillán ( $36^{\circ} 32^{\prime} \mathrm{S}, 71^{\circ} 55^{\prime} \mathrm{W}, 217$ masl). It is important to point out that there is a gap of solar radiation data between: i) January and March of 1996, and ii) April and November of 1997. Therefore, these periods were not included for the analysis in the discussion section for the Penman-Monteith FAO and Priestley-Taylor methods because they depend on the solar radiation data for $E T_{\mathrm{o}}$ estimations.

\section{$E T_{o}$ estimation methods}

Background and assumptions (Savage et al., 2009). The transfer of water vapour between a surface and the atmosphere of the surface is a fundamental aspect of the water balance of a plant community. From a consideration of the simplified energy balance of a vegetable surface, in the absence of advection flux density and neglecting biochemical and physical storage by the canopy in comparison with other terms:

$R_{n e t}+L E+H+S=0$ 
where $R_{\text {net }}, L E, H$ and $S$ are the net irradiance, latent energy flux density, sensible heat flux density and soil heat flux density, respectively. Al terms are in $\mathrm{W} / \mathrm{m}^{2}$. Combining the energy balance equation with the definition of the Bowen ratio (Bowen, 1926):

$$
L E=\frac{-\left(R_{n e t}+S\right)}{1+\beta}
$$

and

$$
L E=-\frac{\beta\left(R_{n e t}+S\right)}{1+\beta}
$$

where $\beta \neq-1$. When $\beta \rightarrow-1$, (2) and (3) cannot be applied and $R_{\text {net }}+S \rightarrow 0$ in (1). Assuming similarity between the exchange coefficients for $H$ and $L E$ :

$$
\beta=\frac{\gamma d T}{d e}
$$

where $\gamma$ is the psychrometric constant in $\mathrm{kPa} /{ }^{\circ} \mathrm{C}, d T$ is the profile air temperature difference in ${ }^{\circ} \mathrm{C}$ and $d e$ is the profile water vapour pressure difference in $\mathrm{kPa}$. Both differences are averaged, typically over $20 \mathrm{~min}$. If, in (4), $\beta=-1$, then $-d e=\gamma d T$ or $d \theta=d e+\gamma d T=0$ where the equivalent temperature $\theta(K)$ is defined by:

$$
\theta=T+\frac{e}{\gamma}
$$

where $T(K)$ is the air temperature and $e$ in $\mathrm{kPa}$ is the water vapour pressure. The psychrometric constant may be written as $c_{\mathrm{p}} P / \varepsilon L$ where $c_{\mathrm{p}}$ is the specific heat capacity of air at constant pressure in $\mathrm{Jkg}^{-10} \mathrm{C}^{-1}, P$ is the atmospheric pressure in $\mathrm{kPa}, \varepsilon=0.622$ is the ratio of the molecular mass of water vapour to that of dry and $L$ is the specific latent energy of vapourisation ( $\cong 2.45 \mathrm{MJkg}^{-1}$ at $\left.20^{\circ} \mathrm{C}\right)$. When the Bowen ratio $\beta=\gamma d T / d e=\left(c_{\mathrm{p}} P / \varepsilon L\right) d T / d e$ equals -1 , then $c_{\mathrm{p}} d T+L d q=0$ in terms of specific humidity $q\left(\mathrm{kgkg}^{-1}\right)=w /$ $(1+w)$, where mixing ratio $w=\varepsilon e /(P-e)$ or $c_{\mathrm{p}} d T+(\varepsilon L / P)$ $d e=0$ are in terms of water vapour pressure $e$. Noting that an adiabatic process is defined as one in which no energy is added or removed and considering what is referred to as a pseudoadiabatic process at constant pressure (a process used in meteorology), Byers (1974) showed that $c_{\mathrm{p}} d T+$ $L d q=0$. Hence, since $\beta=-1$, then $c_{\mathrm{p}} d T+L d q=0$, the conditions under which $\beta=-1$ are pseudoadiabatic and isobaric. For the application of (2) and (3), data collecting during these conditions must be identified, excluded if necessary and replaced if possible. Such pseudoadiabatic conditions are depicted on the psychrometric chart by wet-bulb temperature isolines, since for such isolines de/dT $=-\gamma$ or $d \theta=0$. Furthermore $\beta=-1$ implies $H=$ $-L E$ and therefore that the available energy is zero which corresponds to adiabatic conditions. Also, assuming adiabatic conditions prevail for which $H+L E=0$ and hence $R_{\text {net }}+S=0$ from (1), $1+\beta=0$ is a possibility using (2).

Penman Monteith FAO (Allen et al., 1998). The PMF method is a traditional and standard method. It uses terms such as $i$ ) the aerodynamic foliage resistance to relate the altitude of the meteorological instruments with the altitude of the crops, and $i$ ) the estomatic resistance to the minimum transpiration, as a function of the type of crop and its altitude. In general terms, the following equation defines $E T_{\mathrm{o}}$ as the sum of evapotranspiration by radiation, plus the aerodynamic evapotranspiration, as shown in (6):

$E T_{o}=\frac{0.408 \Delta\left(R_{n}-G\right)+\gamma \frac{900}{T+273} u_{2}\left(e_{s}-e_{a}\right)}{\Delta+\gamma\left(1+0.34 u_{2}\right)}$

where $\Delta$ is the slope of the curve of saturation vapour pressure in $\mathrm{kPa}^{\circ} \mathrm{C}^{-1}$ to the mean air temperature $T ; R_{\mathrm{n}}$ is the net radiation received over the surface or field being studied in $\mathrm{MJm}^{-2} \mathrm{day}^{-1}$, which is comprised by the short wave solar radiation $R_{\mathrm{ns}}$ minus the net long wave radiation $R_{\mathrm{nl}}$ both in $\mathrm{MJ} / \mathrm{m}^{2}$ day; $G$ is the heat flow or thermal flow from the floor in $\mathrm{cal} / \mathrm{m}^{2}$, which was considered negligible in this study because the magnitude of the heat wave under the surface of reference is very small; $\gamma$ is the psychrometric constant in $\mathrm{kPa}^{\circ} \mathrm{C}^{-1} ; u_{2}$ is the wind speed at $2 \mathrm{~m}$ high in $\mathrm{m} / \mathrm{s}$; and $\left(e_{\mathrm{s}}-e_{\mathrm{a}}\right)$ is the deficit of vapour pressure in $\mathrm{kPa}$, which is determined by the difference between the vapour pressure saturation of the air $e_{\mathrm{s}}$ at temperature $T$ minus the vapour pressure of the air mass $e_{\mathrm{a}}$ at a temperature $T$.

Priestley-Taylor. This method is a simplified version of the PMF, which proposes that reference evapotranspiration for a humid surface under conditions of minimum advection, is a function of $\Delta$ and $\gamma$ of the difference between the net radiation received by the soil minus the heat flow from it $\left(R_{\mathrm{n}}-G\right)$, and of a non-dimensional empirical correction factor $\alpha$, which Priestly and Taylor (1972) estimated in the 
range between 1.08 and 1.34, with a mean of 1.26 (value used in this study):

$$
E T_{o}=\alpha \frac{\Delta}{\Delta+\gamma}\left(R_{n}-G\right)
$$

Hargreaves-Samani. Samani (2000) and Hargreaves and Allen (2003) developed an expression to estimate $E T_{\mathrm{o}}$ as a function of the solar radiation that reaches the ground level and the mean temperature of the air, which is defined as follows:

$$
E T_{o}=\beta \alpha R_{a} \sqrt{T D}\left(T_{\text {mean }}+17.8\right)
$$

where $\beta$ is an adjustment coefficient of the equation, which varies according to the area where it is used; $\alpha$ is an empirical coefficient which can be estimated as a function of the difference between the maximum and minimum daily temperature $\mathrm{TD}$ in ${ }^{\circ} \mathrm{C} ; R_{\alpha}$ is the net radiation received at the highest level of the atmosphere over the study area in $\mathrm{MJ} / \mathrm{m}^{2}$ day ${ }^{1}$, and $T_{\text {mean }}$ is the mean daily temperature in ${ }^{\circ} \mathrm{C}$ in the area analyzed. The estimation of $\alpha$ and $\beta$ was done using daily measures of radiation and temperature. These values were previously estimated by Mercado (2006) as $\alpha$ $=0.144$ and $\beta=0.0124$.

\section{Analysis of the different methods results}

Once estimated the daily $E T_{\mathrm{o}}$ according to the methods described above and for the period $1996-2008$, the $E T_{\text {o }}$ moving averages were calculated for periods of 30,7 , and 3 days. Then the moving averages of same time frames were compared with the reference evapotranspiration series, obtained from pan evaporation data $E T_{\mathrm{o}} B$, and using a pan coefficient of 0.85 (Mercado, 2006), which was estimated for the zone as a constant for the year. In order to complement the analysis and validate the methods, the differences between the $E T$ ostimated using a particular method $X_{\mathrm{e}}$ and the $E T_{\mathrm{o}} B$ values $X_{\mathrm{o}}$ (used as the benchmark) were quantified. The measurements used to evaluate the differences between series were the Root Mean Squared Error RMSE and the Relative Difference RD, expressions (9) and (10) respectively.

$$
R M S E=\sqrt{\frac{1}{N} \sum_{i=1}^{N}\left(X_{e}-X_{o}\right)^{2}}
$$

$R D=\frac{R M S E}{\bar{X}_{o}} 100$

where $N$ is the number of data within the series and $\bar{X}_{\mathrm{o}}$ is the average of $E T_{0} B$ series.

\section{Results and discussion}

Firstly, a graphical comparison was performed for the daily $E T_{\mathrm{o}}$ series obtained from the methods PMF, PT, and HS, with the $E T_{0} B$ series from pan evaporation used as benchmark (Figure 1). It shows how the HS method tends to underestimate the $E T_{\mathrm{o}}$ values, especially during dry season (boreal summer, December to March). The PMF and PT methods present better results, but with a slight tendency to underestimate (PT method) and overestimate (PMF) the $E T_{\text {o }}$ values. Tabari (2009) presented similar results for a cold-humid region in Iran with annual precipitation of $1359 \mathrm{~mm}$ and an average temperature of $16^{\circ} \mathrm{C}$, similar to the zone in this study, where the author observed that the HS method was the least accurate in relation to the reference values for the study area. In addition, these results are consistent with the ones reported by Jensen et al. (1990), Amatya et al. (1995), and Trajkovic and Kolakovic (2009), where the method HS was observed and defined as deficient for humid zones.

Further insight can be obtained by examining the differences between $E T_{\text {o }}$ estimated values from each method and the $E T_{0} B$ data series quantified for different moving averages (Table 1). Additionally, for the 7-day moving average, scatter plots are shown with a linear regression analysis between $E T_{\mathrm{o}}$ and $E T_{\mathrm{o}} B$ for each method and for three different periods: $i$ ) the whole year, $i$ ) the irrigation season (October-March), and iii) the humid season (AprilSeptembre). On one hand, quantifying the differences using moving averages allows us to compare the methods through statistical parameters (Salas et al., 1980), while scatter plots and regression analysis allows us to evaluate the quality of the methods being studied. Therefore, precise estimations should result in a linear correlation with 1:1 slope and a high correlation coefficient, while a deficient method should vary away from the 1:1 slope and/ or present a lower correlation coefficient, indicating more dispersion and uncertainty in estimations. 

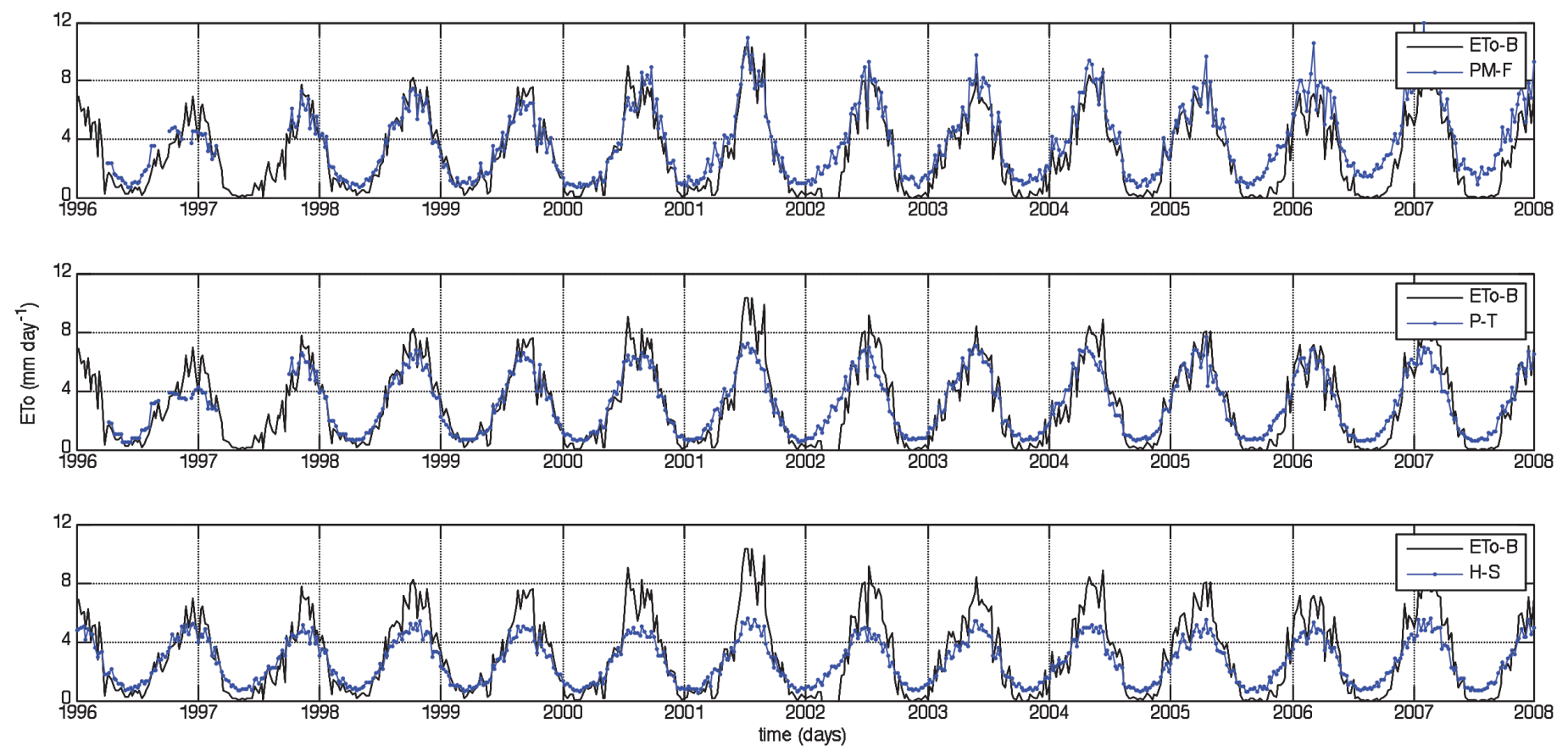

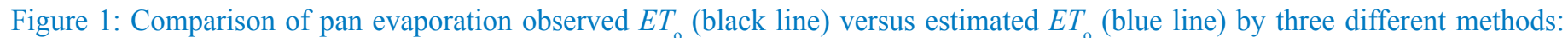
Penman Monteith FAO PMF, Priestley-Taylor PT and Hargreaves-Samani HS at Chillán, Chile during the 1996 to 2008 period.

Table 1 shows that when increasing the time length of moving averages, the quality of $E T_{\mathrm{o}}$ values improves for the three methods being studied, suggesting that the errors in the $E T_{\text {o }}$ estimation and the variability within the series tends to be compensated with larger temporal length of evaluation. This is logical because as the time length increases, the local effects are reduced, and the temporal variability, not included into the equations, or not measured by the instruments, is smoothed.

Table 1: Differences between estimated $E T$ values by different methods with the ET $B$ for different moving averages. RMSE: Root Mean Squared Error, RD: Relative differences of the Penman Monteith - FAO PMF, Priestley-Taylor PT, and Hargreaves-Samani HS methods for estimating reference evapotranspiration.

\begin{tabular}{|c|c|c|c|c|c|c|}
\hline \multirow{2}{*}{$\begin{array}{c}\text { Mobile } \\
\text { Mean } \\
\text { days }\end{array}$} & \multicolumn{2}{|c|}{ PMF } & \multicolumn{2}{c|}{ PT } & \multicolumn{2}{c|}{ HS } \\
\cline { 2 - 7 } & $\begin{array}{c}\text { RMSE } \\
\mathrm{mm} / \text { day }\end{array}$ & $\begin{array}{c}\text { RD } \\
\%\end{array}$ & $\begin{array}{c}\text { RMSE } \\
\text { mm/day }\end{array}$ & $\begin{array}{c}\text { RD } \\
\%\end{array}$ & $\begin{array}{c}\text { RMSE } \\
\text { mm/day }\end{array}$ & $\begin{array}{c}\text { RD } \\
\%\end{array}$ \\
\hline 30 & 1.07 & 34.7 & 1.04 & 33.8 & 1.19 & 38.8 \\
\hline 7 & 1.22 & 39.7 & 1.01 & 32.8 & 1.36 & 44.6 \\
\hline 3 & 1.26 & 40.9 & 1.17 & 37.9 & 1.49 & 48.3 \\
\hline 1 & 1.47 & 47.8 & 1.41 & 46.0 & 1.67 & 54.3 \\
\hline
\end{tabular}

From the analysis of values and figures of RMSE and
$\mathrm{RD}$, it can be concluded that the RMSE values for the HS method are the result of an underestimation of $E T_{\text {o }}$, becoming the model with the values that are the furthest from the benchmark. The PMF and PT methods present better goodness of fit values, but the PT model presents the smallest differences in relation to the $E T_{\mathrm{o}} B$ values (Table 1).

The regression analysis presented in Figure 2 reveals that the HS method underestimates the $E T_{\text {o }}$ for reference values above $2 \mathrm{~mm} /$ day, and it overestimates $E T_{\text {o }}$ for values below $2 \mathrm{~mm} /$ day (Figure 2c). Such differences are more noticeable for the humid period and slightly reduced for the irrigation period (see slope of the linear regression in Figure $2 \mathrm{f}$ and $2 \mathrm{i}$ respectively). However the differences are still important in comparison to the $E T_{0} B$ values. A similar behaviour, but with a slope closer to $1: 1$, can be observed with the PT method and for the whole period under analysis (Figure 2b). The PT method underestimates for values above $3.5 \mathrm{~mm} /$ day and overestimates for values below 3.5 $\mathrm{mm} /$ day. This trend was also reported for humid zones by George et al. (2002) and Tabari et al. (2013). On the other hand, the PMF method presents a more logic behaviour (1:1 slope), but with the disadvantage of an offset in the regression curve, indicating a tendency to overestimate the $E T_{\text {o }}$ values by an average of $0.8 \mathrm{~mm}$ (Figure 2a). 


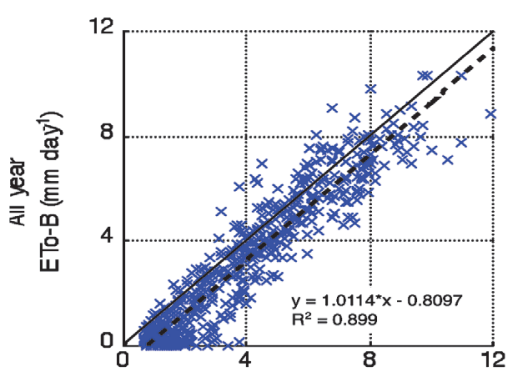

(a)

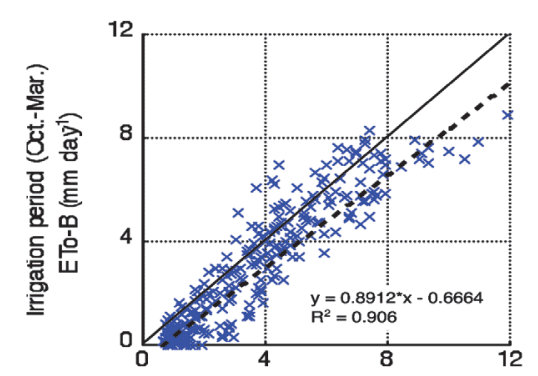

(d)

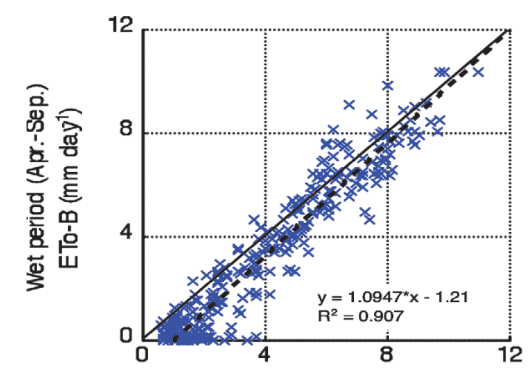

(g) PM-F (mm day')

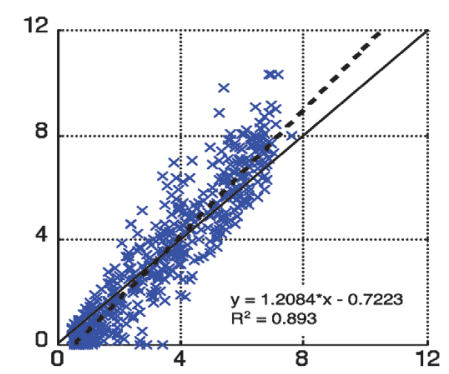

(b)

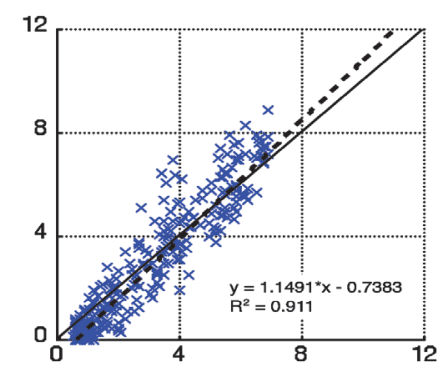

(e)

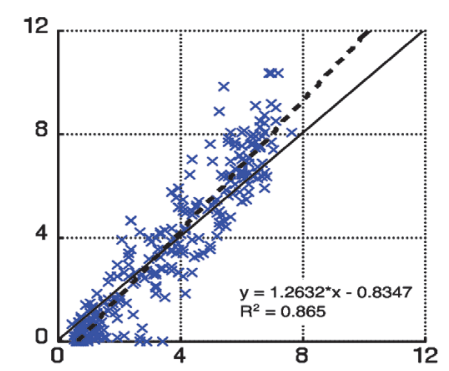

(h) P-T (mm day')

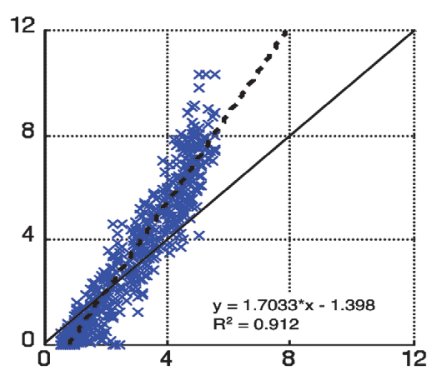

(c)

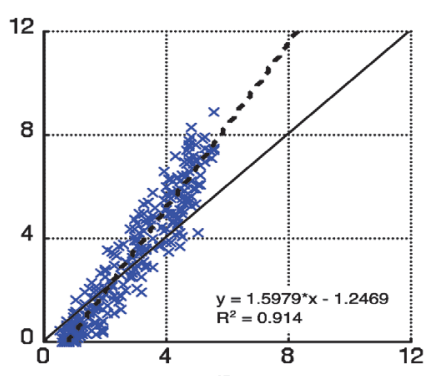

(

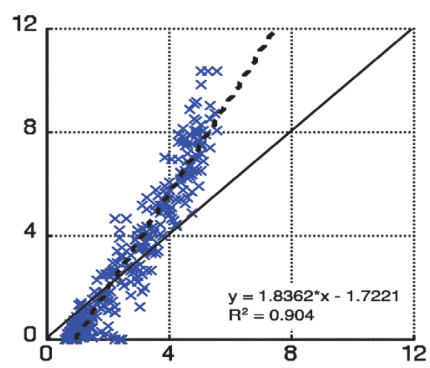

(i) $\mathrm{H}-\mathrm{S}\left(\mathrm{mm} \mathrm{day}^{-1}\right)$

Figure 2: Scatter plots of observed pan evaporation $E T_{0}$ versus estimated $E T_{0}$ with three methods and for three periods. Top row show results for the whole year, the middle row for the irrigation season (October-March) and the bottom row for the wet season (AprilSeptember). Left column show results for the Penman Monteith FAO PMF, the central column for the Priestley-Taylor PT, and the right column for the Hargreaves-Samani HS methods.

For the irrigation season the PT method appear to be better than the PMF method since the regression is more close to the 1:1 slope and lesser dispersion in the results is observed (Figure $2 \mathrm{~d}$ and 2e). These results suggest that the PMF method is better if $E T_{0}$ values are intended to estimate for the whole year, however if more precision is required for the irrigation season, PT seems to be more adequate. When analyzing only the determination coefficient $\mathrm{R}^{2}$, it is observed that the best correlation is obtained with the HS method (Figure 2c, $\mathrm{R}^{2}=0.912$ ). However, when complementing this result with the prior analysis it can be concluded that the method presents a smaller dispersion in relation to the $E T_{\mathrm{o}} B$ values. In other words, this method reproduces the temporal variability in a better way than the other methods but with a higher deviation from the benchmark values, which suggests that this method is inadequate for $E T_{\text {o }}$ estimation in the area of Chillán. Comparing the PMF and PT methods with benchmark data, it is clear that PMF presents better scores (in terms of $\mathrm{R}^{2}$ and RMSE) than the PT. However, PT presents smaller relative differences. Furthermore, considering that the series of data used as benchmark contains a great number of zeroes during periods where there was no registered pan evaporation due to rain (see Figure 1 during winter seasons, and Figure 2 in the $E T_{0} B$ axis), there should be a deviation in the slope of the regression curves that is only observed in the PT method, making it the most representative of the evaporation processes for the Chillán area.

\section{Conclusions}

The comparison between PMF, PT and HS methods with the reference evapotranspiration values obtained from pan 
evaporation shows that the PT and PMF methods present the better adjustments to the reference evapotranspiration values than the HS method for the agricultural area of Chillán. Evaluating comparative differences between the PMF and PT methods was observed that the PT presented the smallest relative differences and an expected and realistic behaviour in the $E T_{\mathrm{o}}$ estimations, and moreover showed the closest estimation of $E T_{\mathrm{o}}$ values for the irrigation season. Therefore, the PT method can be prescribed as the most adequate for estimating $E T_{\text {o }}$ for the agricultural area of Chillán. In order to obtain more precise results, it is necessary to incorporate a correction factor to the pan evaporation series, in particular for those periods where the measured values were $0 \mathrm{~mm}$. This problem is observed on rainy days, where the evaporation pan registers the difference between evaporation and precipitation instead of the real evaporation generating values close to 0 . This alters the results, and could be observed on slopes above 1 and/or displacement of the regression curve.

\section{Acknowledgements}

The authors would like to thank to the Instituto Nacional de Investigaciones Agropecuarias INIA-Quilamapu, and to Dr. Octavio Lagos from the Department of Water Resources of Universidad de Concepción, for providing the data for this study. This project has been partially founded by the Project CENSOR, EC-INCO-CT2004-511071.

\section{References}

Allen, R., Pereira, L., Raes, D. and Smith, M. (1998). Crop evapotranspiration - Guidelines for computing crop water requirements. FAO Irrigation and Drainage paper 56, UN-FAO, Rome 300(9), D05109

Amatya, D.M., Skaggs, R.W., Gregory, JD. (1995). Comparison of methods for estimating REF-ET. Journal of Irrigation and Drainage Engineering 121(6), 427-435

Bowen, I.S. (1926). The ratio of heat losses by conduction and by evaporation from any water surface. Physical Review 27(6), 779-787

Byers, H.R. (1974). General Meteorology. $4^{\text {th }}$ ed. McGraw Hill, New York

Droogers, P. and Allen, R. (2002). Estimating reference evapotranspiration under inaccurate data conditions. Irrigation and Drainage Systems 16(1), 33-45
George, B.A., Reddy, B.R.S., Raghuwanshi, N.S. and Wallender, W. (2002). Decision support system for estimating reference evapotranspiration. Journal of Irrigation and Drainage Engineering 128(1), 1-10

Hargreaves, G. and Allen, R. (2003). History and evaluation of Hargreaves evapotranspiration equation. Journal of Irrigation and Drainage Engineering 129(1), 53-63

Hube, G. (1989). El fenómeno de la evapotranspiración en la cuenca del Bío Bío. Master thesis, Universidad de Concepción

Jensen, M.E., Burman, R.D. and Allen, R.G. (1990). Evapotranspiration and irrigation water requirements. ASCE Manual 70:332-333

Kottek, M., Grieser, J., Beck, C., Rudolf, B. and Rubel, F. (2006). World map of the Köppen-Geiger climate classification updated. Meteorologische Zeitschrift 15(3), 259-263

Mercado, G. (2006). Estimación de la evapotranspiración de referencia utilizando información de temperatura del aire. Master thesis, Universidad de Concepción

Novoa, R., Villaseca, S., Del Canto, P., Rouanet, J., Sierra, C. y Del Pozo, A. (1989). Mapa Agroclimático de Chile. Instituto de Investigaciones Agropecuarias, Santiago, Chile

Priestley, C. and Taylor, R. (1972). On the assessment of surface heat flux and evaporation using large scale parameters. Monthly Weather Review 100(2), 81-92

Rana, G. and Katerji, N. (2000). Measurement and estimation of actual evapotranspiration in the field under Mediterranean climate: a review. European Journal of Agronomy 13(2), 125153

Salas, J.D., Delleur, J.W., Yevjevich, V. and Lane W.L. (1980). Applied modeling of hydrological time series. Water Resources Publications, Michigan, USA

Samani, Z. (2000). Estimating solar radiation and evapotranspiration using minimum climatological data. Journal of Irrigation and Drainage Engineering 126(4), 265-267

Sánchez, J.M., Caselles, V. and Scavone, G. (2008). Merging micro-meteorology and Landsat imagery to monitor daily evapotranspiration at a regional scale. Tethys 5, 37-46

Savage, M.J., Everson C.S. and Meterlerkamp, B.R. (2009). Bowen ratio evaporation measurement in a remote montane grassland: data integrity and fluxes. Journal of Hydrology 376(1), 249-260 
Sumner, D. and Jacobs, J. (2005). Utility of Penman-Monteith, Priestley-Taylor, reference evapotranspiration, and pan evaporation methods to estimate pasture evapotranspiration. Journal of Hydrology 308(1): 81-104

Tabari, H. (2009). Evaluation of reference crop evapotranspiration equations in various climates. Water Resources Management 24(10), 2311-2337

Tabari, H., Grismer, M.E. and Trajkovic, S. (2013). Comparative analysis of 31 reference evapotranspiration methods under humid conditions. Irrigation Science 31(2), 107-117

Trajkovic, S. and Kolakovic, S. (2009). Evaluation of reference evapotranspiration equations under humid conditions. Water Resources Management 23(14), 3057-3067
Wang, K. and Dickinson, R.E. (2012). A review of global terrestrial evapotranspiration: Observation, modeling, climatology, and climatic variability. Reviews of Geophysics 50(2):RG2005, 1-54

Xiaoying, L. and Erda, L. (2005). Performance of the PiestleyTaylor equation in the semiarid climate of North China. Agricultural Water Management 71(1), 1-17 